\title{
La temprana recepción del Diálogo de la lengua en España y unos versos en elogio del español*
}

\section{Early Reception of Diálogo de la lengua in Spain and some Verses in Praise of Spanish}

\section{Lola Pons Rodríguez}

Universidad de Sevilla

ESPAÑA

lolapons@us.es

[Hipogrifo, (issn: 2328-1308), 8.2, 2020, pp. 727-744]

Recibido: 16-06-2020 / Aceptado: 03-09-2020

DOI: http://dx.doi.org/10.13035/H.2020.08.02.42

Resumen. Este artículo estudia la huella que la lectura del Diálogo de la lengua de Valdés pudo dejar en uno de sus primeros poseedores, el humanista y profesor Álvar Gómez de Castro, que atesoró en su biblioteca el considerado codex optimus de la obra. Se editan y estudian los versos en encomio del español que redactó Gómez de Castro y se ubican en su contexto de producción y de recepción, la Universidad de Alcalá, cuya posición ideológica en el ecuador del siglo XVI resulta fundamental para entender los versos de Gómez de Castro y su contacto con el Diálogo.

Palabras clave. Álvar Gómez de Castro; Juan de Valdés; Diálogo de la lengua; humanismo; Universidad de Alcalá.

Abstract. The article studies the tracks that the reading of Diálogo de la lengua could leave on one of its first owners, Álvar Gómez de Castro, who treasured the codex optimus of Valdés work in his library; specifically, some laudatory verses on Spanish language written by Gómez de Castro are edited and studied. The ideological position of the University of Alcalá in the $16^{\text {th }}$ century is also taken in account,

* Este trabajo se desarrolla dentro del proyecto FFI2016-74828-P que codirijo desde la Universidad de Sevilla La escritura elaborada en español de la Baja Edad Media al siglo XVI: traducción y contacto de lenguas (Historia15). Agradezco sus atinadas sugerencias a los evaluadores del artículo. 
as it is essential to understand the verses of Gómez de Castro and his contact with the Dialogue.

Keywords. Álvar Gómez de Castro; Juan de Valdés; Diálogo de la lengua; humanism; University of Alcalá.

La vida del humanista toledano Álvar Gómez de Castro (1515-1580) coincide en algunos puntos biográficos con la de Juan de Valdés. Ambos son manchegos (Valdés de Cuenca, Gómez de Castro de Santa Olalla, en Toledo), ambos proceden de familias judeoconversas, ambos pasaron por la Universidad de Alcalá de Henares, ambos se formaron en letras y en lenguas antiguas, ambos tuvieron hondas preocupaciones religiosas (Gómez de Castro se ordenó sacerdote) y ambos firmaron obras que los eruditos de la llustración se afanaron por recuperar. Entre ellos, que nunca coincidieron en vida, hubo un eslabón librario que los vinculó para siempre y que es motivo de redacción de estas páginas: Gómez de Castro poseyó uno de los manuscritos del Diálogo de la lengua que circularon por España antes del siglo XVIII.

En estas páginas rescatamos una composición en castellano que escribió Gómez de Castro, esforzado poeta neolatino, en elogio al español, y mostramos en qué sentido coinciden o difieren su contexto de producción y sus topoi con los del Diálogo. Contextualizaremos la obra de Gómez de Castro en el entramado humanístico de su tiempo y su producción metalingüística sobre lenguas clásicas (§ 1), profundizaremos en la relación entre Gómez de Castro y la obra valdesiana, particularmente su Diálogo de la lengua (§ 2), y editaremos de forma completa el poema panegírico sobre el castellano que Gómez de Castro escribió (§ 3.1), que estudiaremos en sus contenidos y tópicos (§ 3.2.) y en su posible relación con el Diálogo antes de terminar con unas conclusiones (§ 4).

1. Las líneas iniciales de un artículo de hace casi ya un siglo firmado por el archivero toledano Francisco San Román (1928) decían de Álvar Gómez de Castro que era entre los humanistas españoles «si no de los más olvidados, sí de los menos conocidos»; casi un siglo después, la tesis de Alvar (1979) sobre la poesía latina de este autor, el libro de Ignoria Pepe sobre sus sonetos (1979), la traducción al castellano de alguna de sus obras (como la biografía de Cisneros, en edición de Oroz Reta, 1984) y algunas monografías (Vaquero Serrano, 1993) nos han hecho completar muy notablemente nuestro conocimiento sobre la producción de este autor y sobre su círculo amistoso e intelectual, en el que figuraban docentes de intereses similares a los suyos: así, los catedráticos de Retórica y de Griego Juan Petreyo y Francisco de Vergara, el destacado erasmista Luis de la Cadena (canciller de la Complutense) o el poeta Juan Hurtado de Mendoza.

Gómez de Castro ha quedado para la historia del humanismo español del siglo XVI como un afanado profesor de menores (en el Colegio de San Ildefonso de Toledo) y mayores (en la Universidad de Alcalá de Henares y en Santa Catalina en Toledo), responsable de una inacabada edición de las Etymologiae isidorianas y de un comentario a san Ambrosio, autor de una biografía latina del cardenal Cisneros y de una abundante obra poética hispanolatina así como de algún texto tratadístico. 
Fuera de su producción pública están sus cartas (con historiadores, helenistas y otros letrados de su tiempo) y sus varios repertorios de papeles: apuntes personales que glosan libros, anotan y traducen pasajes de obras clásicas, copian epigrafía cercana, contrastan en listados el léxico griego o latino con el español y ayudan a construir el perfil de Gómez de Castro como un obsesivo escrutador de textos grecolatinos, docente que compila en cuantos libros lo rodean todos los materiales útiles para sus clases. Sus misceláneas, cuadernos de trabajo hoy guardados en la Biblioteca Nacional y en la de San Lorenzo de El Escorial, son reveladoras de un modo de estudiar más asistemático que el desarrollado por los studia humanitatis de Italia, menos orgánico en su forma de sumar transcripciones, traducciones, explicaciones y excursos sobre textos latinos o griegos.

En esos materiales tan numerosos no hay referencias que apunten a un interés particular de Gómez de Castro como gramático por la lengua española. Obviamente, en lo que parece una derivada lógica de quien estudia y enseña lenguas que son ajenas a la suya materna, se encuentran algunas muy dispersas observaciones sobre el español, que surgen sobre todo en sentido contrastivo a partir del análisis de propiedades de la lengua latina o griega'. Si, como afirma Alvar (1982, p. 197), «Álvar Gómez no aspira, ni mucho menos, a hacer una gramática latina o griega» en sus frecuentes anotaciones sobre estas dos lenguas, aún menos pretendía generar contenido gramatical propio sobre la lengua española.

Tampoco es particularmente relevante su obra literaria en castellano, al menos si la comparamos en cantidad con la que produjo en latín. Gómez de Castro firma en castellano un tratado sobre las vestales dirigido a María de Mendoza, varios sonetos y algunas composiciones poéticas de ocasión. En esa obra castellana figuran ciertos versos que escribió como parte del panegírico poético que rodeó la visita del arzobispo de Toledo a la Universidad de Alcalá de Henares; a ellos nos dedicaremos infra.

2. El testamento de Gómez de Castro recuperado por San Román (1928) nos permite descubrir en su biblioteca varios volúmenes que sirvieron a Gómez de Castro como obras de referencia: el Universal vocabulario de Alonso de Palencia, la Gramática nebrisense, junto con obras de medicina, metafísica, tratados en romance como la Agricultura de Herrera, obras literarias como el Laberinto de fortuna de Juan de Mena y un foco bibliófilo erasmista cuyo origen estaría en su amigo, el catedrático de Filosofía Juan de Vergara, que llegó a tratar personalmente a Erasmo en Flandes y con el que se carteó: de él atesoró algunas obras como el Tratado de las ocho cuestiones, que compartieron anaqueles con las paráfrasis de los evangelios de Erasmo.

El testamento de Gómez de Castro es claro también en una cuestión, punto principal para la argumentación que se construye en nuestro trabajo: Gómez guar-

1. Así, Alvar (1982, p. 195) recupera, por ejemplo, los datos que el manuscrito K-III-28 de El Escorial ofrece respecto del uso de las letras c y g en español, tanto en un sentido panegírico («da nombre a los más elevados conceptos: caridad, concordia, compañerismo») como en su pronunciación, asunto que también ocupa a Gómez de Castro al respecto de las letras y y j. En general, las notas que se localizan sobre el español en los textos de este autor son más bien de tipo léxico o fónico, y en escasa medida gramaticales. 
daba un testimonio del Diálogo de la lengua y registra a Valdés como su autor. Teniendo en cuenta las dudas que generó la autoría del Diálogo de la lengua en el siglo XIX, la aportación del testamento de Gómez de Castro es en el primer testimonio temprano que de forma indubitable daba como noticia inequívoca la autoría valdesiana. Gómez de Castro no solo menciona el Diálogo en el listado de obras que constituyen su legado, sino que da indicación de la localización y destinatario que a su muerte le quiere asignar:

Ansi mesmo la Gramatica de Romançe de Antonio de Nebrija quiero que se enquaderne con el dialogo de valdes de la lengua española, que tengo escrito de mano, y que se ponga en la libreria de la dicha santa yglesia, lo qual ella mandara enquadernar en tablas pues es libro raro para guardarse alli y si en esto oviere olvido, mando que a mi costa se enquaderne y se ponga en el dicho lugar (San Román, 1928, p. 553).

De los manuscritos antiguos que transmiten el Diálogo, el más importante es sin duda el hoy conservado en la BNE (MSS/8629), conocido como M: escrito en papel italiano por varias manos que atestiguan su familiaridad con usos gráficos y fonéticos propios de la península itálica, pudo ser copiado en el entorno de Valdés o estar en contacto con el autógrafo; este es también el más temprano de los testimonios, «padre» del resto de ellos, copiados ya sin duda en España. Para San Román $(1928$, n. 14) el manuscrito que poseyó Gómez de Castro era sin duda el de la Nacional, atribución que basa en las siete apostillas, según él autógrafas del propio Alvar Gómez, que figuran en varios pasajes del manuscrito². Es difícil reconstruir la forma en que el manuscrito valdesiano viajó desde Italia a la biblioteca de Gómez de Castro, pero se hace necesario apuntar (remito para estos detalles a la edición en prensa del Diálogo de la lengua de Pons Rodríguez) a una figura de enlace que estuviera en el entorno de Gómez de Castro.

El hecho de que Juan Páez de Castro (1510-1570) poseyera otro de los manuscritos del Diálogo y que Jerónimo Zurita manejara también uno de ellos ayuda a empezar a configurar la primera red de lectores de que gozó el texto metalingüístico valdesiano en España. Mucho antes de la edición mayansiana de 1736, el Diálogo fue leído y circuló en España, al menos entre los humanistas de finales del XVI; ello no supone, con todo, pensar en una difusión del Diálogo mucho más allá de sus meros poseedores o de sus discípulos más directos. La connotación de heterodoxia religiosa que tenía la obra de Valdés en el XVI explicaría una cierta clandestinidad en la transmisión de sus escritos, que terminó afectando, no hay duda, a la única obra no religiosa de Valdés, expurgada, con todo, en los pocos pasajes que eran sospechosos de heterodoxia.

2. Queda sin resolver la cuestión de en qué estado se encontraba M cuando lo consultó Gómez de Castro. Sabido es que entre los folios 82-83 de este manuscrito hay una laguna que se ha explicado por el mero azar de un accidente o como censura a cierto pasaje en que se contaría una anécdota sobre el conde de Ureña; cabe recordar que Gómez de Castro también cuenta (en De rebus gestis) anécdotas sobre el hijo de ese conde de Ureña, Pedro Girón y Velasco, que se codeó con Cisneros. Gómez de Castro debió de consultar el manuscrito ya con esa laguna, pues a la mano "epsilon" se atribuye la anotación «aqui falta hoja» puesta a pie de una página. 
Vista la relación de libros que componen la biblioteca de Gómez de Castro y el fruto que de ellos extrae, atestiguado en su obra pública y en sus cuadernos de trabajo, el Diálogo de la lengua no debió de ser obra tenida por capital en el estudio del humanista toledano, pero de ella Gómez de Castro pudo sacar algunas enseñanzas que dejaron rastro en sus escritos.

3. Si San Román (1928, p. 544) subrayaba en la producción de Gómez de Castro su «doble personalidad de historiador y humanista» y atribuía a la primera de sus facetas «una serie de relaciones contemporáneas sobre fiestas y solemnidades celebradas en Alcalá y Toledo con motivos muy diversos», el texto que analizamos aquí pertenece sin duda a la segunda categoría, la de humanista.

3.1. En 1546, Juan Martínez Guijarro (1477-1577) fue promovido al arzobispado de Toledo. El nuevo arzobispo, latinizado en su nombre como Silíceo, combinaba en sí un sólido rigorismo religioso -impone la instauración del estatuto de limpieza de sangre- con una elevada formación académica: estudia en París lógica y dialéctica y es de su autoría el Ars Arithmetica (1514), obra que le dio fama de buen matemático. En el mismo año en que es nombrado arzobispo de Toledo, sale de su sede primada y acude, el 15 de abril, a la Universidad de Alcalá. Su visita parece algo más que un protocolario desplazamiento de cortesía: Silíceo acude en Alcalá al palacio arzobispal, donde estaban doña María y doña Juana, las hijas de Carlos V (Silíceo fue maestro del príncipe Felipe, futuro Felipe II, de 1534 hasta 1541), y visita también la Universidad. El gobierno que la diócesis de Toledo ejercía sobre la plaza de Alcalá había desencadenado en el pasado desagradables tensiones entre universidad e iglesia; tras la muerte del arzobispo Fonseca en 1534, con su sucesor Juan Pardo de Tavera habían arreciado los desencuentros, y el canónigo de Toledo y catedrático de Filosofía de la Universidad de Alcalá Juan de Vergara estaba ese año aún encarcelado por la Inquisición. A Gómez de Castro le correspondió destensar relaciones por parte de la universidad. Silíceo fue saludado en Alcalá en la esperanza de que mejorasen estas relaciones; el tiempo demostró que todo ello fue un vano intento.

La obsequiosidad al nuevo arzobispo quedó manifiesta en el exorno de arcos que se hizo en la Universidad y en la realización de una justa poética en su honor, recogida dentro de un volumen en cuarto de 157 páginas titulado Pvblica laetitia, qva dominvs loannes Martinus Silicaeus Archiepiscopus Toletanus ab Schola Complutensi Susceptus est ${ }^{3}$ impreso por Juan Brocar y con encabezamiento en las páginas impares de «Scholae complutensis». El texto tiene una factura de gran calidad y contiene en su interior varios grabados simbólicos4; se compone

3. Se localizan bastantes ejemplares (British Library, Cambridge, Real Academia de la Historia; a partir de este ejemplar hizo su edición Barrantes, 1877), Hispanic Society, Biblioteca de la Universidad de Granada (esta, con signatura a4 A-H8 I6, está digitalizada en la ciberpágina de Cervantes virtual; otra copia se encuentra digitalizada en Google libros). Cfr. Martín Abad, 1991, p. 537, registro 364 para más detalles de ubicación así como para la fórmula de colación.

4. La portada se acompaña del escudo con la empresa de Juan Martínez Silíceo, un grabado del trigrama IHS sobre pedernal rodeado de llamas, cubiertas por timbre del capelo con borlas y el lema eximunt tangentia ignem ('eslabón me es toda cosa', 'por el contacto, desprendemos fuego'; ver López Poza, 
de una serie de piezas latinas de variada índole y de diversa autoría. Pese a que el libro se dedica sobre todo a glosar el terceto Sepa cierto la virtud / que será remunerada / aunque más esté encerrada5, solo una pequeña parte (páginas 71 a 75) de la Pvblica laetitia está escrita en romance; en concreto, lo están unos tercetos endecasílabos («Comendación de las glosas vulgares»), unas glosas en verso al terceto propuesto en la contienda, que incluyen además dos sonetos, y una última parte «Glosa más dilatada sobre los versos castellanos» (Es como sueño esta vida / es una sombra, es un tras...).

Nos referiremos en lo que sigue a los mencionados tercetos de la Comendación. Aunque nada dentro del libro declara explícitamente que sea de Gómez de Castro la autoría (podría ser de algún otro de los poetas participantes), parece asumido que estamos ante una de las varias obras de ocasión firmadas por este autor ${ }^{6}$. Esta, con todo, presenta una curiosa singularidad dentro de su producción en general y dentro del propio libro en que se inserta: estamos ante un elogio de la lengua vulgar que, por su fecha, es una de las más tempranas loas escritas a la lengua española. La razón de esta loa tiene un sentido dentro del XVI, el siglo de la valoración de los romances, de la dignificación de los vulgares. Pero, para este caso concreto, la loa parece construirse por una razón interna. Las primeras justas poéticas alcalaínas fueron convocadas por el amigo de Álvar Gómez de Castro, Juan Hurtado de Mendoza en 1542; en las de 1546, se había producido una doble novedad: apareció como convocante el rector de la Complutense, Jorge Genzor (Pascual Barea, 2010), y este autorizó que tales justas pudieran ser compuestas en lengua castellana. La propia reglamentación del Certamen quinto de las justas deja clara esa autorización y la justifica: «hispanica Musa lepore, salibus, festivitate, argutiis, cum graia latinque contendere nonnunquam potest» (p. 7 de Pvblica laetitia) ['Puesto que la musa hispánica puede competir en agudeza, donaires y finura hay que darle lugar en estos certámenes']. Considerada desde esta perspectiva, la Comendación se explica como preliminar que defiende la existencia de glosas en castellano a las coplas, funciona dentro de la Pvblica laetitia como un prólogo justificativo al uso del español en las glosas que seguían.

2017, que registra también la aparición del símbolo en otros libros así como en portadas arquitectónicas). En la portada del libro aparece el dístico «Si quicquid tangit ferrum est, atque excitat ignem. Qui fit ab insculpto hoc nomine quantus erit?». En su parte final, el libro contiene otra serie de interesantes grabados (en total suman 24) que resumen las virtudes del arzobispo, todas ellas resaltadas por sus correspondientes epigramas latinos. Cfr. Martínez-Burgos (1988) para la descripción detallada de la iconografía.

5. Su sentido figurado se basa en la propia imagen del pedernal o sílex que está en el nombre del arzobispo, ya que «como el fuego está oculto en el pedernal y salta al toque del eslabón, así la virtud escondida en la persona del arzobispo brota al toque divino» (Alastrué Campo, 1990, p. 69).

6. Fue responsable, al menos, de otras cuatro, entre ellas el Recibimiento que la imperial ciudad de Toledo hizo a la reina doña Isabel cuando entró en ella (Toledo, 1561; esta última cuenta con la edición de Fernández Travieso, 2007). 
Tanto Alcina (1979) como Alvar (1979) han editado parcialmente el poema; el bibliófilo extremeño Vicente Barrantes (1877, p. 153) lo había editado ya de forma completa, pero parece que tal edición pasó desapercibida para la crítica. A continuación, editamos de forma completa sus 38 estrofas $^{7}$ con una ligera adaptación gráfica ${ }^{8}$.

Comendación de las glossas vulgares al reverendíssimo señor arçobispo de Toledo en tercetos castellanos.

Al príncipe de prestes, al primado d'España, al que a las musas da reposo, salud y dicha buena y más estado. El benigno lector, el que está ansioso de ver en su lenguaje algún estilo, aquestas glossas lea codicioso. La musa çahareña el duro filo de mi ronca vihuela no le espante, que más delgada hebra no la hilo. $¡ \mathrm{O}$, quién me diesse brío tan bastante! $¡ \mathrm{O}$, quién ya me inspirasse melodía que sonasse en poniente y en levante! Esfuérçate algún tanto, musa mía, publica de tu lengua su tesoro, en vano no se vaya aqueste día. En la griega se halla el bello coro mezclado con cantares y cordura, la gravedad en Roma y en su foro. En todos los negocios, la ventura es mucho lo que puede y adelanta, de los sabios las lenguas son hechura. Aquel divino Homero en griego canta, y muchos otros más que aquí me dexo. Marón en los romanos nos encanta. En nombre de mi lengua yo me quexo aquí, con boz llorosa y triste acento, que nunca tuvo yedra sino texo. Agora me parece que ya siento

7. Se trata de tercetos encadenados al estilo de la terza rima con una última estrofa de cuatro versos, de ahí el resultado final de 115 versos.

8. Aplicamos tildes, regulamos como $s$ la s larga, respetamos la distribución de b y $v$, así como la de ss, modernizamos ph, th y ch equivalente a / $/$ / (choro), desarrollamos las abreviaturas sin marca, modernizamos mayúsculas, intervenimos en la unión y separación de palabras así como en la puntuación, marcamos las contracciones (despaña> d'España) y corregimos dos erratas (v.5. lengaje > lenguaje; v. 18 granedad > gravedad). No intervenimos en la vacilación de átonas, el uso de $h$ (oh se presenta como 0 , según reza en la fuente) o la distribución gráfica del impreso original. Para el verso 66 resuelvo con hiato un pasaje que resultaría hipométrico y para el verso 85 marco en corchetes la velar de agora pues de otra forma sería hipermétrico y es válido por la fecha pensar en un ahora. 
brotar nuevos pimpollos de laureles, guiados con furor y con aliento. Aquestos, por ventura, en sus papeles darán alguna muestra, algún dechado del lenguaje español, de sus niveles. ¿Ay gracia o ay donaire tan salado en otra alguna lengua que no cobre sabor nuevo en la nuestra trasladado? En copia de palabras quien la sobre no siento, aunque las dos contino leo que me mostrarán bien si fuera pobre. Antes alguna vez, quando me veo forçado en la lición que aquí professo, con latín declararm'e por rodeo,

al romançe me voy claro, confiesso mi poca abilidad y luego hallo palabras convenientes al processo. Las agradables metáforas me callo, las sentencias embueltas con refranes no digan lo que suelen. Cada gallo... Los dichos apazibles de truhanes los motes y las gracias y bivezas ¿a quién no quitarán dos mil afanes? Para las cosas grandes tus altezas que tienes se pareçe, lengua mía, quando el predicador dize grandezas. En mi niñez y juventud bivía un varón, que los más bien conocieron, por nombre Dionysio se dezía.

Testigos me serán los que le oyeron de aquella magestad con que hablava, y aquel torrente grande que en él vieron. Vocablos, parecía que innovava, según muchos dezía, grandemente los fines de la lengua dilatava.

Aqueste nos monstrava claramente la fuerça de la lengua que tenemos, y qüán poco se sabe de gente. Aquí con la latina la ponemos, el ínclito rector lugar le ha dado: con lenguas favorables lo loemos.

Si de las cosas proprias no me agrado y en esto mi juizio tengo sano, en nada la romana se ha agraviado. Señor reverendíssimo, la mano le dad para ayudarla, pues merece 
tener de vos favor todo el humano.

Contino la virtud loada crece

y el exercicio que es favorecido

en alto en un momento resplandece.

Antes olvidará el ave su nido,

las aguas hazia tras yrán bolviendo, que se ponga Mecenas en olvido.

Aqueste, los poetas requiriendo

su ocio y sus ingenios sustentando,

ha hecho que el latín esté biviendo.

Estamos otro tal a[g]ora esperando

que haga nuestra lengua valerosa,

su ayuda y su favor encaminando.

El sobervio edificio, la costosa

madera y cantería, los bestiones

algunos les parece eterna cosa.

$Y$ al fin, andando siglos, los montones

de cantos solo quedan, o ruinas

como arbitraria piedra de mojones.

«Aquí devieron ser algunas minas»,

el caminante que passa va diziendo,

«he aquí de la alta torre las esquinas».

Otros de más quilate, no queriendo

gastar en piedras muertas, dexan renta

para la casta donzella proveyendo.

¡Ay Dios, qué santa obra, quánta cuenta

de aqueste tal varon aver devía!

por falta de poetas no se mienta.

En el canto de aquestos biviría,

exemplo a los demás eternamente,

en sus medidos versos dexaría.

¿Por donde conocemos a la gente

passada, quál fue griego, quál romano?

¿Por qué se sabe agora del valiente?

Tuvieron escriptores a la mano

que nos dieron noticias de sus cosas,

y los libran del diente del gusano.

Aquí, señor, tus obras valerosas

en que dichosamente así te empleas,

los versos las publican y las prosas.

A ti, lector, las damos que las veas. 
El texto comienza con una invocación a Silíceo como dedicatario (vv. 1-3) y al lector, al que ya en el segundo terceto se asocia con el tema principal de la pieza: su deseo de ver en «su lenguaje», el romance, «algún estilo» podrá ser satisfecho con las glosas que siguen a la Comendación. La mención a una musa çahareña que puede juzgar con rechazo la ronca vihuela del poeta hace aparecer el topos del empequeñecimiento ligado a la exigencia de una musa que se califica con un adjetivo, zahareña ('áspera'), aplicado en el XVı a cetrería indómita y, por extensión, a las damas, y que fue, de hecho, comentado de forma explícita en el Diálogo valdesiano, cuando Marcio le pregunta a Valdés por su posible etimología árabe:

En una copla, muy donosa a mi ver, he leído dos vocablos que no me suenan bien. No sé lo que vos juzgáis dellos; los vocablos son halagüeña y çahareña [...]:

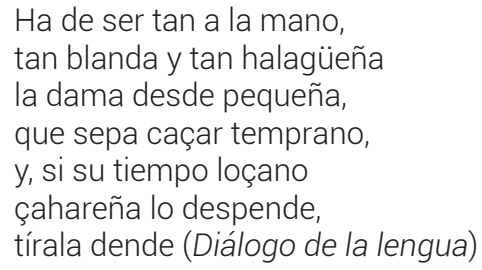

El imperativo en segunda persona a la musa («Esfuérçate algún tanto, musa mía») para llamar al objetivo de los versos («publica de tu lengua su tesoro») sirve al autor para encomiar la necesidad de que la decisión de poner el castellano dentro de las justas poéticas en posición compartida con el latín trasvase la propia ocasión de las justas y que «en vano no se vaya aqueste día». El cuerpo central de la composición se dedica a valorar al español en relación con las otras lenguas de cultura: le faltan los panegíricos con que cuenta el griego («en la griega se halla el bello coro / mezclado con cantares y cordura») y el latín (que tiene «la gravedad en Roma y en su foro»). El verso «de los sabios las lenguas son hechura» resume el sentir del poema y la queja, también tópica, de la falta de auctoritates en español que sean comparables a los papeles que cumplieron Homero o Virgilio (al que Gómez de Castro, por rima, no llama por su nomen sino por su cognomen Marón). El castellano «nunca tuvo yedra sino texo», y ahí alude Gómez de Castro a la tópica idea del tejo como conífera venenosa ${ }^{9}$, esto es, no tuvo buenos árboles a que arrimarse en imitatio; sigue con las imágenes en torno a la vegetación: véase la esperanzada mención a los «nuevos pimpollos de laureles, / guiados con furor y con aliento» que ve brotar en la escritura del castellano; para Alvar (1982, p. 208) tales versos son una muestra de que «el humanista comprende desde muy pronto, ya en 1546, que algo nuevo está sucediendo en el mundo cultural español, que se avecina una edad dorada para los estudios y para la lengua romance». Garcilaso de la Vega había muerto diez años antes y su fama como poeta latino y castellano ya era notabilísima; bien pudiera ser Garcilaso, o alguno de los propios amigos de

9. El tejo es tópicamente asociado a la toxicidad de su fruto y tenido por ello por árbol venenoso. Autoridades (s. v. texo): 'Árbol parecido al haya o al abeto [...]. Es tenido por venenoso y tanto que aun su sombra dicen que hace daño'. 
Gómez de Castro (el gran mecenas y peor poeta Juan Hurtado de Mendoza) unos de esos pimpollos a los que se alude.

Gómez de Castro concreta la capacidad del español como lengua fuente de traducciones, lo que no resultaba ajeno a su propia trayectoria como traductor docente ( $¿$ Ay gracia o ay donaire tan salado / en otra alguna lengua que no cobre / sabor nuevo en la nuestra trasladado?») ${ }^{10}$, su riqueza léxica (aunque para glosarla recurra, paradójicamente, al latinismo copia), su estilo poco circular (en relación con las lecciones de latín «lición que aquí profeso» por la Universidad en que es pronunciada esta loa). Con el tópico del no diré pasa revista a las metáforas, los refranes, vivezas, dichos, motes, gracias, en fin, los juegos verbales que se adjudican a los truhanes, pero a los que disculpa: «¿a quién no quitarán dos mil afanes?» frente a los asuntos de alto contenido y estilo que se expresan como «quando el predicador dize grandezas». El gusto por los refranes es hallazgo erasmista que a Gómez de Castro pudo llegar no forzosamente por Valdés, sino por otras de sus lecturas de impronta erasmiana ${ }^{11}$. En cualquier caso, cabe recordar que el refrán que se menciona con reticencia en la Comendación ("cada gallo...») es uno de los más de cien refranes que cita Valdés en el Diálogo, justamente en boca de su propio personaje ${ }^{12}$ :

Mayor donaire es querer vos ser juez en la provincia donde no sabéis las leyes. ¿No avéis oído dezir que cada gallo cante en su muladar? (Diálogo de la lengua).

La única referencia a una auctoritas castellana aparece al hablar de las grandezas de un predicador: «un varón, que los mas bien conocieron, por nombre Dionysio se dezía» con que Gómez de Castro se refiere al catedrático de Sagrada escritura en la Universidad de Alcalá, Dionisio Vázquez, fallecido en 1539, y tenido por el mejor predicador de su tiempo, a quien Gómez de Castro declara haber conocido en su juventud; ello le sirve para alabar su dictio («aquella magestad con que hablava, / y aquel torrente grande que en él vieron») y las bondades de su inventio («Vocablos, parecía que innovava, / según muchos dezía»), capaces de someter a tensión creativa al español y mostrar sus capacidades («Aqueste nos monstrava claramente / la fuerça de la lengua que tenemos») ${ }^{13}$. No pasemos por alto el hecho de que Vázquez conoció y difundió las razones erasmistas.

10. Recordemos que él mismo, que solía traducir del griego al latín, había ejercido de traductor ocasional al español; cfr. Alvar (1982) para sus traducciones ocasionales de epigramas de Marcial, la Antígona de Sófocles, las Silvas de Estacio o algún fragmento de Homero, en todos los casos parece que con finalidad fundamentalmentes escolar y docente, esto es, para poner textos a disposición de su alumnado. Más propia de ejercicio premeditado es la traducción inversa, del romance al latín, como hace con Ausias March.

11. Recordemos que en su testamento (San Román, 1928, p. 551) Gómez de Castro lega un «libro de mano de cosas del doctor Vergara y cartas de Erasmo».

12. El refrán, que apela al derecho de cada uno a disponer en su propia casa o disciplina, tiene un fundamento en la tradición latina (el proverbio clásico gallus in sterquilinio suo plurimum potest), figuraba ya en el Seniloquium y se testimoniaba también en los principales refraneros del XVI y XVII.

13. El propio Álvar Gómez en su biografía latina sobre Cisneros (De rebus gestis a Francisco Ximenio Cisnerio) lo pondera en términos antonomásicos como un predicador sin parangón («Tandem post lon- 
La lengua romance, que Dionisio Vázquez ha probado estar capacitada para la expresión más impecable, es la que aquí se elogia porque «el ínclito rector [de la Universidad Complutense] lugar le ha dado»). No parece esta ser referencia a que el castellano fuera privilegiado como lengua de la enseñanza en la universidad frente al latín ${ }^{14}$ sino a que la propia justa dignifica al castellano como lengua en la que se puede mostrar el ingenio y la capacidad. Tendrían que pasar más de veinticinco años para que Francisco Sánchez de las Brozas, recién estrenado su cargo de catedrático de Retórica en la Universidad de Salamanca, publicara impresas sus Anotaciones a Garcilaso, empresa novedosa por la dignificación que supone de la nueva poesía castellana.

Los elogios a Silíceo continúan en el centro de la composición («Señor Reverendíssimo la mano / le dado para ayudarle, pues merece / tener de vos favor todo el humano»). Igual que Mecenas favoreció a la lengua latina, dice Gómez de Castro, «estamos otro tal agora esperando / que haga nuestra lengua valerosa, / su ayuda y su favor encaminando». La poesía elegiaca sobre ruinas, tan de moda en ese tiempo, hace también presencia aquí: «Y al fin andando siglos los montones / de cantos solo quedan o ruinas / como arbitraria piedra de mojones, / Aquí devieron ser algunas minas / el caminante que passa va diziendo / he aquí de la alta torre las esquinas»); los fragmenta arquitectónicos sirven para mostrar que el pasado glorioso contrasta con la destrucción presente y que lo perdurable (scripta manent) está en la memoria escrita. Apela a los escritores como forma de resistir en la memoria: «libran del diente del gusano». Y termina Gómez de Castro: «Aquí señor tus obras valerosas / en que dichosamente asi te empleas, / los versos las publican y las prosas. / A ti, lector, las damos que las veas».

3.3. ¿Había leído ya Gómez de Castro el Diálogo valdesiano cuando escribió estas coplas en 1546? Afirmarlo tendría consecuencias no solo para el mejor entendimiento del contexto de estos tercetos sino también (de mayor alcance) para poder situar el manuscrito italiano del Diálogo en España antes de 1546, esto es, en fecha tan temprana como al menos diez años después de haber sido escrito. Hay varios motivos en la Comendación que podrían ser de huella valdesiana: tal vez el uso del adjetivo zahareña, tal vez la seguridad en la vindicación de los refranes... Hubiera

gam consultationem, diuino numine rem suam curante, Dionysius Vasquius Toletanus Augustinianu ordinis sosalis, ingenii monstrusi vir, qui tunc in sacris concionibus apud Hispanos principatum tenebat, ac propterea Carolo Çesari in primis carus», fol. 223v»). Más referencias a Dionisio Vázquez se hallan en los papeles manuscritos de Gómez de Castro (ms. K-III-31 10) de El Escorial que contienen un «Comentario de fray Dionisio Vázquez al doctor Diego de León de la Universidad de Alcalá sobre los médicos». Esta recurrencia en la loa a Vázquez es una de las razones que entendemos sirve para reforzar la atribución de autoría de esta comendación a Gómez de Castro. Aunque no se haya puesto en duda, no hay ninguna indicación dentro de la Publica laetitia que atribuya esta pieza particularmente a Gómez de Castro, y si bien Alvar (1979) ya señalaba que resultaba «difícil precisar qué partes corresponden al humanista de Santa Olalla», lo cierto es que para la Comendación no se han expresado dudas autoriales. 14. De hecho, como recoge Gil Fernández (1981), hay variados testimonios quinientistas de cómo en las aulas universitarias españolas se explicaban las materias (incluso el latín) usando el castellano. Así, contamos con el testimonio de Navagero, hacia 1524, que solo salvaba de esa práctica a la Universidad de Alcalá. 
sido o no ya leído por Gómez de Castro al componer la Comendación, el humanista debió de encontrar en el Diálogo de la lengua ideas nuevas y confirmación de otras que por convicción o formación ya tenía. Recordemos que Gómez de Castro defendió con insistencia la utilidad de la lengua griega dentro de las aulas universitarias ${ }^{15}$ y la obra valdesiana daba un lugar de preeminencia al griego en el solar lingüístico ibérico; de hecho, proscribía el uso de la lengua española en el itinerario formativo de quienes quieren hacerse letrados de lenguas clásicas ${ }^{16}$.

Podemos buscar nuevas huellas de la lectura del Diálogo de la lengua en otro escrito de Gómez de Castro: el Parecer acerca de prohibición de libros de poesía y otros (BNE 18634/13 y copia en BNE 13009), redactado por Gómez de Castro a instancias de la Inquisición; se trata de un excelente retrato de «la valoración moral que cree aplicable a la literatura seglar, tanto la clásica latina como la castellana, en la línea marcada por la regula VII del Index tridentino de Pío IV» (Moreno y Sainz de la Maza, 2000, p. 60)17. La postura de Gómez de Castro es, con todo, bastante tolerante sobre los modos de aplicar estas recomendaciones. Tal actitud se observa con claridad cuando, al empezar comentando a Plauto y Terencio, reconoce que está bien «que en los estudios no los lean a los muchachos», pero que no es necesario que los quitaran de la circulación puesto que «si los vedaran absolutamente fuera quitar toda la imitaçión y propriedad de la lengua latina» (Russell, 1982, p. 222).

La lectura de ese texto revela puntos de coincidencia con los tratados por Valdés en su Diálogo. Cierto es que no estamos ante opiniones particularmente singulares o distantes de las que circulaban en los círculos humanistas, pero no es ninguna extravagancia sostener que en el fundamento o el alimento de algunas de esas opiniones pudo estar la lectura del Diálogo de la lengua ${ }^{18}$.

Castro repasa a algunos autores latinos y dedica la segunda parte de su texto a «los libros vulgares», para detenerse, obviamente, en los que están escritos o traducidos en castellano. Valora positivamente a Bembo y Boccacio, entre otros, y de los propiamente en castellano distingue tres grupos: los devotos (de los que apenas se ocupa), los de "caballerías y cosas fingidas» y los de poesía. En este último ámbito, Gómez de Castro coincide con Valdés en algunos de sus juicios. Así, cuando salva a la Tragicomedia de la Celestina (dice Valdés en el Diálogo: «De

15. Gómez de Castro «trata de demostrar que, gracias a esta afición por la cultura clásica, progresa la comunidad entera (de todos modos, no debemos dejarnos cegar por el espejismo: una y otra vez estas alabanzas, esta demostración de la necesidad de los profesores de griego, acaban en una solicitud para que se aumente su sueldo que apenas alcanza para mantener a los familiares)» (Alvar, 1982, p. 210). 16. Así, Alvar (1978, p. 132) recoge el testimonio de que entre las cartas de Gómez de Castro está la alusión a la educación de un muchacho llamado Luis César con el que ejerce como tutor y cuyos conocimientos e inteligencia alaba, pero del que dice que debe corregir y perfeccionar su latín hablado, su letra y ortografía, y que asegura vencerá estos defectos «si se acostumbra a hablar siempre latín y se le prohíbe tajantemente el uso de la lengua vulgar».

17. El texto, de corta extensión y redacción poco elaborada, fue descubierto en 1903 por Serrano y Sanz, pero erróneamente atribuido a Zurita; fue luego estudiado por Russell (1982), quien esclarece meridianamente la atribución al Eulaliense.

18. En otros casos Gómez de Castro rechaza o aprueba obras que Valdés no conoció: por ejemplo, cuando critica la Diana de Montemayor (1559). 
Celestina me contenta el ingenio del autor que la comenzó y no tanto el del que la acabó») y en lo que se refiere a la Cárcel de amor (Valdés es displicente: «El estilo desse me parece mejor») y la Cuestión de amor (Valdés comentaba: «Muy bien la invención y muy galanos los primores que ay en él; y lo que toca a la cuestión no está mal tratado»). Su análisis de la poesía repite una idea de la Comendación sobre la falta de auctoritates en español: «Solo vna cosa querría que se aduirtiese en esto: que auiendo en la lengua Española tan buenos ingenios, está muy falta de libros bien escritos y que la ubieran illustrado, como se ha hecho en la Italiana y en la Francessa» (Russell, 1982, p. 224). Solo reconoce como posibles obras españolas canónicas en cuanto a temas de amores a la Celestina, y a los versos de Boscán, Garcilaso, Diego de Mendoza y el Cancionero general casi al completo; todas ellas son aprobadas y quedan fuera de censura según su criterio. Valdés en el Diálogo había citado también encomiásticamente a Garcilaso («Huélgome que os satisfaga, pero más quisiera satisfazer a Garcilasso de la Vega con otros dos cavalleros de la corte del emperador que yo conozco») y a algunos de los poetas del Cancionero general («tengo por buenos muchos de los romances que están en el Cancionero general, porque en ellos me contenta aquel su hilo de dezir»).

Interesa particularmente la coincidencia con Valdés en los juicios sobre las caballerías. Gómez de Castro condena estas ficciones, pero salva de ellas a los cuatro primeros libros del Amadís de Gaula; Valdés hacía lo mismo en el Diálogo («Entre los que an escrito cosas de sus cabezas, comúnmente se tiene por mejor estilo el del que escrivió los quatro libros de Amadís de Gaula»), aunque también añadía a su juicio favorable otras dos novelas de caballerías (Palmerín y Primaleón).

Hay un material adicional que podemos citar sobre la lectura personal y las notas que Gómez de Castro había hecho sobre el Amadís. Como han mostrado Moreno y Sainz de la Maza (2000), Gómez de Castro copió en una de sus misceláneas conservadas en la Real Biblioteca San Lorenzo de El Escorial varios fragmentos de los primeros libros del Amadís titulándolos con lemas que resumían aspectos morales claves de su desarrollo argumental. Resulta muy relevante para el asunto que nos ocupa el hecho de que en tales notas Gómez de Castro glose y anote algunas voces y estructuras del Amadís que le resultaban llamativas, seguramente por razones lingüísticas más que de contenido: así, en la morfosintaxis, tú fueste más sabio y osado en mi fecho que yo lo fuera, o por la orilla del yelmo contra hondón, donde la forma en -ra con valor pluscuamperfecto y el hondón locativo parecen reclamar su atención del mismo modo que a Valdés le suscitaba comentarios la forma en -ra de Amadís ( «No me suena bien viniera por avía venido, ni passara por avía passado») y el hondón del polo segundo de Juan de Mena. Igualmente es relevante la anotación que Gómez de Castro hace sobre el adverbio aína en su nota 18: a la frase de Amadís «a vos qué haze de yo ir aína ni paso» Gómez de Castro añade «por lo que dicen apriesa o a espacio» (recuérdese que Valdés señalaba en sus preferencias léxicas que decía «antes presto que aína») y el hecho de que la nota 22 «y salíase dél cada que quería» coincide con el apunte valdesiano: «Cada que por siempre dizen algunos, pero no lo tengo por bueno». Otras de esas glosas también coinciden con apreciaciones valdesianas, como la anotación 12 de Gómez de Castro sobre el lunar muy claro de Amadís glosado por el Eulaliense como por 
la luna (Valdés también había reparado en ese pasaje, pero por una cuestión argumental: «También es descuido dezir que el rey mirava la hermosura del cuerpo de Helisena con la lumbre de tres antorchas que estavan ardiendo en la cámara, no acordándose que avía dicho que no avía otra claridad en la cámara sino la que de la luna entrava por entre la puerta»).

Ambos coinciden en la detección de elementos del Amadís que eran arcaizantes para la época de Gómez de Castro y lo eran para Valdés; puede ser que ambos reaccionen ante una lengua como la del Amadís que, además de antigua, era geolectalmente occidental (Domingo del Campo, 1982) frente al geolecto central, manchego, que representan tanto Valdés, conquense, como Gómez de Castro, toledano.

4. Termina nuestra incursión en la obra castellana de uno de los primeros lectores que el Diálogo de la lengua tuvo en España. En la biografía de Álvar Gómez de Castro, la redacción de esta Comendación en castellano resulta completamente menor y aparentemente irrelevante. Con todo, y a la luz de su posesión de un manuscrito del Diálogo de la lengua, estos versos son motivo para una justificada comparación entre el elogio a la lengua valdesiano y el hecho por Gómez de Castro.

La búsqueda de coincidencias es en la literatura todo un género (el del rastreo de lugares comunes) y en la investigación biografista un ejercicio que puede ser ridículamente extremoso si basa su empeño en trazar líneas de contacto causales entre lo que pueden ser simples y meras casualidades. Entre Valdés y Gómez de Castro se dan coincidencias biográficas lógicas entre quienes provienen de territorios cercanos (ambos son manchegos), se han formado en una misma universidad alcalaína y han participado de un horizonte similar de lecturas y libros disponibles. Las coordenadas compartidas se plasman en lecturas comunes y en un universo humano que ambos conocieron, aunque en diferentes momentos: Valdés era mayor que Gómez de Castro (pero no más de 10 o 15 años, su fecha de nacimiento es insegura).

Esos dos momentos y esa diferencia de edad pueden justificar también dos actitudes vitales e ideológicas muy distintas, exhibidas a su manera en los elogios que Valdés y Gómez de Castro hacen sobre el español. Valdés entra en la Universidad de Alcalá en 1526, cuando aún el prestigio de Erasmo en España era elevado, con Francisco de Vergara (que había tratado personalmente a Erasmo en Flandes) sirviendo de enlace entre el erasmismo universitario y el de la corte. Gómez de Castro accede a la misma universidad en 1531, un año después de que se inicie el proceso inquisitorial contra Vergara, de que haya sido detenido su hermanastro Bernardino de Tovar, y dos años después de que Diego de Uceda fuera detenido por la Inquisición y torturado en un auto de fe. Entre ambos momentos está el año de 1529, que había supuesto la caída del favor del inquisidor Alonso Manrique, el freno al erasmismo y el inicio de la interesada vinculación entre el erasmismo castellano y las ideas de los comuneros. La universidad que con Gattinara y Alfonso de Valdés había sido un centro propagador de ideas erasmistas y de alabanza al emperador era en la época de Gómez de Castro un entorno distinto. 
Comparten Valdés y Gómez de Castro unas mismas lecturas: Mena y la Celestina, la ficción de las caballerías... pero si en el primero vemos un ejercicio de crítica literaria en el comento ponderado dentro de un diálogo al modo renacentista, en el segundo las lecturas castellanas aparecen glosadas en manuscritos de trabajo o comentadas en un texto que pretende guiar el expurgo inquisitorial. Ambos, sí, denuestan las caballerías, pero el vehículo que transmite ese rechazo revela una actitud de posicionamiento elitista y culto en Valdés y una actitud de observancia y acato del rigor en Gómez de Castro. Si para Valdés el esfuerzo está en desmitificar al Amadís y a Nebrija y elevar a los refranes como modelo de lengua, para Álvar Gómez de Castro el refrán es garante de agudeza y el modelo de decir está en la lengua de la predicación.

Ambos tuvieron un séquito en torno a su magisterio: el de Valdés, nobiliario y cortesano, el de Gómez de Castro, universitario y, en menor medida, aristócrata, pero los lugares de ambos grupos de discípulos informan sobre su grado de integración en el sistema ideológico de la época: Valdés en Nápoles, donde se instala tras haber publicado una obra sospechosa por su aliento erasmista, el Diálogo de doctrina cristiana, Gómez de Castro en Alcalá. Los propios tórculos de la imprenta dan cuenta de esa diferencia en los dos tiempos de cada uno. Juan de Brocar, el impresor de la Pvblica laetitia, es cuñado de Miguel de Eguía, el impresor que había ayudado en su taller a la difusión de la obra erasmista en España, que había sido castigado con prisión por ello y que luego se retractó públicamente: Eguía es el mismo impresor que en 1529 había impreso el Diálogo de doctrina cristiana de Juan de Valdés.

Gómez de Castro es la cara ortodoxa, integrada no sin tensiones en el vigilado sistema educativo y religioso español del momento. Valdés es la cara heterodoxa que el propio sistema había generado unos años antes. Gómez de Castro y los eruditos de su entorno se nutren de muchos de los logros que la generación inmediatamente anterior (la que trató a Cisneros y era coetánea de Dionisio Vázquez o de Eguía) había alcanzado bajo el ojo amenazante de la Inquisición; que Gómez de Castro reconozca el magisterio del predicador erasmista Vázquez es una constatación de que en el estudio particular no se dieron los rigores que la Inquisición provocaba públicamente. La Comendación nos pone, pues, ante el humanismo comme il faut que la universidad que visitaba Silíceo, en una fecha en que está en prisión Vergara y cuando los libros de Barcarrota estaban a punto de ser escondidos, se podía permitir.

Ahora bien, en este escenario de lugares, personas y lecturas que Valdés y Gómez de Castro comparten, la defensa de las lenguas vulgares no resulta una coincidencia casual o espontánea. En ese ambiente complutense se estaba dando un claro cambio de ideología sobre el prestigio literario de las lenguas vulgares. Valdés lo refina en Italia, desde su exilio, y Gómez de Castro lo muestra con el trivial caramelo de unos versos de circunstancia compuestos en un entorno universitario, dentro de un acto de ortodoxia panegírica a una auctoritas de prestigio religioso y académico como Silíceo. Las posibles trazas de Valdés en la obra de Gómez de Castro nos ayudan a perfilar con mayor cuidado la figura de un humanista que, 
entregado a la docencia y al estudio de textos latinos o griegos, no descuidó su formación en romance; desagravió con escritos muy instrumentales (como su Parecer) y meramente de ocasión y efímeros (como la Comendación que aquí nos ha ocupado) la lectura de ficciones en español. Más de treinta años después, otro prelado toledano propiciaba la escritura sobre el español, aunque de forma más directa: el cronista de Indias Juan López de Velasco da a la imprenta en 1582 su Orthografía y pronunciación castellana a instancias del inquisidor general y cardenal de Toledo Gaspar de Quiroga.

El siglo XVIII volvió a hacer coincidir a Valdés y a Gómez de Castro. Los manuscritos de trabajo de Gómez de Castro custodiados en la Nacional y El Escorial conocieron copias descripti dieciochescas debidas al jesuita Andrés Marcos Burriel (1719-1762), que se había carteado con Mayans a propósito de la copia que existe del Diálogo en la biblioteca escurialense. Entre el XVI de nuestros dos autores y el XVIII de los ilustrados que empiezan a estudiar sus manuscritos, el siglo XVII había situado ya a los elogios del español en una dedicación más ociosa que militante. Ya el romance no necesitaba defender su sitio en unos juegos florales ni la questione della lingua era la controversia viva que había sido: «Así es, porque también se puede decir una necedad en latín como en romance, y yo he visto letrados tontos, y gramáticos pesados, y romancistas vareteados con sus listas de latín, que con mucha facilidad pueden enfadar al mundo, no una sino muchas veces». La frase, puesta en boca de un perro llamado Cipión, es de un alcalaíno que también marchó a Italia, pero por haberse metido en una pelea de espada.

\section{BiBLIOGRAFÍA}

Alastrué Campo, Isabel, Alcalá de Henares y sus fiestas públicas (1503-1675), Alcalá de Henares, Universidad de Alcalá, 1990.

Alcina, Juan F., «Tendances et caractéristiques de la poésie hispano-latine de la Renaissance», en L'humanisme dans les lettres espagnoles. XIXe Colloque International d'Études Humanistes, Tours, 5-17 juillet 1976, ed. Augustin Redondo, París, Librairie Philosophique J. Vrin, 1979, pp. 133-149.

Alvar Ezquerra, Antonio, Acercamiento a la poesía de Alvar Gómez de Castro: ensayo de una biografía y edición de su poesía latina, Tesis doctoral, Madrid, Universidad Complutense de Madrid, 1979.

Alvar Ezquerra, Antonio, «Alvar Gómez de Castro, humanista», Revista de Filología Española, LXII, 3-4, 1982, pp. 193-210.

Barrantes, Vicente, Aparato bibliográfico para la historia de Extremadura, tomo 3, Madrid, Establecimiento Tipográfico de Pedro Núñez, 1877.

Domingo del Campo, Francisca, El lenguaje en el «Amadís de Gaula», Tesis doctoral, Madrid, Universidad Complutense de Madrid, 1982. 
Gil Fernández, Luis, Panorama social del humanismo español, Madrid, Alhambra, 1981.

Gómez de Castro, Álvar, Recibimiento que la imperial ciudad de Toledo hizo a la magestad de la reina nuestra señora doña Isabel, hija del rey Enrique II de Francia, cuando nuevamente entró en ella a celebrar las fiestas de sus felicissimas bodas con el rey don Filipe nuestro señor, II deste nombre (Toledo, 1561), ed. Carlota Fernández Travieso, La Coruña, SIELAE / Sociedad de Cultura Vallé Inclán, 2007.

Gómez de Castro, Álvar, Sonetti, edizione critica, introduzione e note a cura di Inoria Pepe Sarno, Roma, Bulzoni, 1979.

López Poza, Sagrario, «Eximunt tangentia ignem», Symbola: divisas o empresas históricas [en línea]. Publicación: 23-05-2017.

Martín Abad, Julián, La imprenta en Alcalá de Henares, Madrid, Arco / Libros, 1991.

Martínez-Burgos García, Palma, «Publica Laetitia, humanismo y emblemática», Cuadernos de Arte e Iconografía, I, 2, 1988, pp. 1-11.

Moreno, Charo, y Sainz de la Maza, Carlos, «Álvar Gómez de Castro y el Amadís de Gaula», Criticón, 78, 2000, pp. 59-74.

Oroz Reta, José, edición, traducción y notas de «De las hazañas de Francisco J. de Cisneros» de Álvar Gómez de Castro, Madrid, FUE, 1984.

Pascual Barea, Joaquín, «Los primeros poetas laureados por la Universidad Complutense (1552-1554): Benito Arias Montano, Juan de Santacruz Cárcamo y Diego de Guevara», en Dvlces camenae: poética y poesía latinas, Granada, Universidad, 2010, pp. 775-803.

Russell, Peter, «Secular Literature and The Censors: A Sixteenth Century Document Re-examined», Bulletin of Hispanic Studies, 59, 1982, pp. 219-225.

San Román, Francisco de Borja, «El testamento de Alvar Gómez de Castro», Boletín de la Real Academia Española, XV, 1928, pp. 543-566.

Valdés, Juan de, Diálogo de la lengua, edición, introducción y notas de Lola Pons Rodríguez, Madrid, Real Academia Española (Biblioteca Clásica), en prensa.

Vaquero Serrano, Carmen, El maestro Álvar Gómez. Biografía y prosa inédita, Toledo, Caja de Ahorros, 1993. 